\title{
A CONSISTÊNCIA DAS MEDIDAS DE PÓS- MATERIALISMO: testando a validade dos índices propostos por R. Inglehart no contexto brasileiro
}

\author{
Ednaldo Ribeiro*
}

\begin{abstract}
Resumo: A teoria do desenvolvimento humano, defendida por $\mathrm{R}$. Inglehart, postula que uma mudança lenta e gradual nas prioridades valorativas individuais tem ocorrido em escala mundial nas últimas décadas. Essa alteração estaria conduzindo à adoção de valores pósmaterialistas que enfatizam a qualidade de vida e a auto-expressão como metas individuais e societais. Os índices construídos por esse pesquisador para medir tais prioridades valorativas, entretanto, têm sido alvo de diversas críticas que questionam a sua validade e consistência. Nesse artigo apresentamos um conjunto de testes envolvendo essas medidas para o caso brasileiro específico, com o objetivo de contribuir com esse debate teórico-metodológico. Utilizando dados produzidos pelo projeto World Values Survey e empregando diferentes técnicas estatísticas, identificamos que as medidas em questão apresentam significativa consistência em nosso contexto.
\end{abstract}

Palavras-chave: desenvolvimento humano, pós-materialismo, valores, medidas de valores, $R$. Inglehart.

Com a publicação de The silent revolution no final da década de 1970, Ronald Inglehart iniciou um programa de pesquisas que hoje pode ser considerado um dos mais profícuos nas Ciências Sociais. A quantidade significativa de trabalhos que defendem e confirmam suas principais hipóteses, mas também os vários críticos

\footnotetext{
* Professor assistente da Universidade Estadual de Maringá (UEM).

E-mail: ednaldorip@uol.com.br
}

Artigo recebido em 30 mar. 2007 e aprovado em 18 jun. 2007. 
que conquistou ao longo do tempo são bons indicadores do impacto de suas proposições.

Desde seu impulso inicial, quase três décadas de investigações empíricas e teóricas se passaram e, repetidamente, a tese da mudança lenta e gradual de um amplo espectro de valores humanos em direção a uma postura pós-materialista tem sido testada a partir de evidências cada vez mais robustas. A teoria do desenvolvimento humano, tal como definida por Inglehart e Welzel (2005), é o resultado atual dessa série de investigações sobre prioridades valorativas.

A tese fundamental defendida pelo autor e seus colaboradores afirma que, a despeito das significativas diferenças culturais existentes entre as nações, uma mudança nos valores estaria ocorrendo associada ao desenvolvimento econômico experimentado a partir da segunda metade do século XX, principalmente pelas sociedades industriais avançadas ou pós-industriais. Tal mudança estaria provocando alterações profundas no campo religioso, no mundo do trabalho, nas relações de gênero, nas normas sexuais e na atividade política (Inglehart, 1977, 1990, 2001; Inglehart e Welzel, 2005).

Nesse artigo, concentramo-nos sobre um aspecto de natureza metodológica fundamental para essa formulação: a validade e consistência dos índices de materialismo/pós-materialismo. Essas medidas são as ferramentas básicas empregadas pelos pesquisadores que seguem essa perspectiva para identificar a suposta guinada pósmaterialista.

Apesar de relativamente consolidados em perspectiva mundial, alguns pesquisadores têm denunciado que tais índices não possuiriam consistência e validade em análises envolvendo nações específicas (Clarke \& Dutt, 1991; Davis \& Davenport, 1999; Clarke et al., 1999). Essas críticas possuem, evidentemente, um poder devastador sobre a tese fundamental da teoria do desenvolvimento 
humano, uma vez que atacam o centro de toda a sua argumentação. A mudança valorativa, caso se aceite a hipótese da inconsistência das medidas, poderia não passar de uma conseqüência desastrosa de equívocos na construção e aplicação do instrumento de coleta de dados.

Com este artigo pretendemos contribuir com esse importante debate mediante a apresentação dos resultados de testes envolvendo os referidos índices no contexto brasileiro. Utilizando dados produzidos pelas duas pesquisas realizadas no Brasil pelo projeto World Values Survey (WVS), valemo-nos de diferentes técnicas estatísticas para verificar a consistência e validade das medidas para a identificação da adesão dos brasileiros aos valores materialistas ou pós-materialistas.

Interessa-nos fundamentalmente verificar se existem dimensões latentes que possam estruturar as respostas fornecidas pelos entrevistados ao conjunto de itens que compõem os índices.

Tendo esse objetivo, dividimos o texto em três seções. Na primeira delas discorremos brevemente sobre os argumentos que sustentam a teoria defendida por Inglehart e seus colaboradores. A exposição dos seus principais conceitos e hipóteses é tarefa fundamental para a adequada compreensão dos testes que desenvolvemos. Na segunda seção, apresentamos alguns detalhes das críticas acima mencionadas. Por fim, na terceira seção, após alguns esclarecimentos metodológicos necessários, partimos para a exposição e discussão dos resultados encontrados.

\section{A teoria do desenvolvimento humano}

A tese da mudança pós-materialista defendida por Inglehart e seus colegas está assentada sobre duas hipóteses fundamentais: a da escassez e da socialização (Inglehart, 1990, 2001; Inglehart \& Welzel, 2005). 
Nas palavras do próprio autor, a primeira delas afirma que "an individual's priorities reflect the socioeconomic environment: one places the greatest subjective value on those things that are in relatively short supply" (Inglehart, 1990, p. 68).

Sendo assim, indivíduos que precisariam quotidianamente lutar para superar constrangimentos à sua reprodução física, devido à escassez de recursos e à violência, tenderiam a se sentir inseguros e, conseqüentemente, priorizariam objetivos relacionados ao desenvolvimento material em oposição a metas transcendentais, subjetivas ou de longo prazo (Inglehart, 1990, 2001; Inglehart \& Welzel, 2005).

Essa linha de argumentação nos remete ao princípio da utilidade marginal decrescente da teoria econômica, associado ao conceito complementar de hierarquia das necessidades de Maslow (1988), segundo o qual as necessidades fisiológicas possuem maior prioridade do que aquelas de natureza não-fisiológica.

Necessidades sociais, intelectuais e estéticas ocupariam posições inferiores nessa hierarquia, o que só poderia ser alterado quando as condições materiais de existência deixassem de ser a principal fonte de preocupação e estresse.

Essa alteração só é possível porque a cultura partilhada por um conjunto específico de indivíduos - ou seja, os valores, prioridades e normas de conduta - não seria estática, adaptando-se ao ambiente em que está inserida através de processos de mutação aleatória e seleção natural (Inglehart, 2001).

Por meio desses processos, aqueles traços culturais que funcionam relativamente bem em um local e contexto específico tenderiam a se reproduzir e expandir em razão de conferirem vantagens de sobrevivência (Dawkins, 1989). As prioridades valorativas que enfatizam as necessidades fisiológicas seriam, 
portanto, traços culturais adaptados e vantajosos em um contexto de insegurança material.

Com a melhoria das condições de sobrevivência física, mudanças coerentes tenderiam também a ocorrer no nível cultural. Prioridades e estratégias vantajosas em um contexto de escassez poderiam não mais produzir efeitos desejados em cenários distintos, sendo gradualmente substituídas por outras, mais compatíveis com a nova configuração.

O impacto das mudanças no nível tecnológico e econômico sobre a dimensão cultural, entretanto, não seria tão simples e direto quanto essa primeira hipótese pode deixar transparecer quando tomada isoladamente.

Inglehart alerta para o fato de que esse processo depende do sentimento de segurança material, que é subjetivo, e não do nível econômico objetivo dos indivíduos. A percepção que uma pessoa desenvolve sobre a sua situação não depende apenas do quanto suas necessidades fisiológicas são satisfeitas, pois os níveis de satisfação de cada um variam enormemente em razão do entorno cultural em que se está inserido e, sobretudo, em que se foi socializado (Inglehart, 1990, 2001).

Sendo assim, o efeito do desenvolvimento econômico não seria verificado imediatamente no plano das prioridades valorativas. A hipótese da escassez, portanto, deveria necessariamente ser interpretada em combinação com a da socialização, segundo a qual,

the relationship between socioeconomic environment and value priorities is not one of immediate adjustment: a substancial time lag is involved because, to a large extent, one's basic values reflect the conditions that prevailed during one's preadult years. (Inglehart, 1990, p. 68). 
Períodos relativamente longos de crescimento e prosperidade econômica, desta forma, não produziriam efeitos significativos nos valores das populações adultas porque elas não se encontram mais nos seus períodos de maior suscetibilidade. O efeito só poderia ser verificado entre os membros das gerações que experimentaram essas melhores condições materiais nos respectivos períodos de socialização infantil e pré-adulta. A mudança das prioridades valorativas só se manifestaria com a mudança geracional (Inglehart, 1977, 1990, 2001).

As mesmas experiências em relação às condições econômicas seriam, portanto, interpretadas de maneiras distintas por indivíduos representantes de diferentes gerações. O que seria considerado como uma situação de segurança para um, poderia não representar o mesmo para outro. Logo, as prioridades defendidas por esses distintos grupos tendem a não ser as mesmas.

Indivíduos que ao longo de sua infância experimentaram situações de profunda insegurança física, quando adultos tendem a continuar priorizando a sobrevivência fisiológica sobre todas as demais necessidades, mesmo quando as condições objetivas não mais justifiquem tal grau de preocupação.

Em síntese, a junção das duas hipóteses defendidas por Inglehart e seus colaboradores compõem a seguinte tese: o crescimento econômico produz efeitos importantes sobre o nível cultural, seja em termos do projeto societal, dos valores individuais ou do padrão de autoridade; porém, esse impacto só pode ser verificado no longo prazo, quando as jovens gerações que experimentaram essas novas condições atingirem a idade adulta.

A partir desses elementos conceituais, os partidários da teoria do desenvolvimento humano têm defendido a tese de que as alterações socioeconômicas que caracterizam as sociedades pós-industriais estariam produzindo mudanças significativas nas 
prioridades individuais, direcionando-as para a ênfase da autoexpressão, escolha humana, autonomia e criatividade (Inglehart \& Welzel, 2005). A busca pelo lucro e pelo crescimento econômico estaria gradualmente perdendo espaço para estratégias alternativas de maximização do bem-estar no mundo contemporâneo.

Esses pesquisadores têm ressaltado que a mudança de rumo não seria conseqüência do fracasso da estratégia anterior, pelo contrário, a busca pelo lucro e desenvolvimento econômico teria alcançado muito êxito, gerando grande produção e bem-estar significativo nas sociedades industriais. Porém, os seus rendimentos teriam decrescido com o passar do tempo (Inglehart, 1990, 2001).

A mudança em curso refletiria a utilidade marginal decrescente do determinismo econômico, expressa nos seguintes termos: “[...] los factores econômicos tienden a jugar un papel decisivo en condiciones de escasez econômica, pero a medida que disminuye esa escasez, otros factores moldean la sociedad en un grado cada vez mayor" (Inglehart, 2001, p. 77)

Mais do que proposição teórica, esse investigador demonstra que essa afirmação possui consistência no campo empírico. Selecionando a expectativa de vida (expectativa de anos de vida ao nascer) como uma medida do êxito das estratégias de maximização do bem-estar e o Produto Interno Bruto (PIB) anual per capita como medida do crescimento econômico, Inglehart chegou a duas conclusões complementares. Primeiramente confirmou a validade da estratégia de maximização do desenvolvimento econômico para a melhoria das condições de vida, uma vez que as variáveis em questão se mostraram claramente associadas. Mas também constatou que o impacto de tal desenvolvimento vai se reduzindo com o avançar do $\mathrm{PIB}$, de modo que se torna decrescente a partir de um determinado ponto. Alcançado um patamar específico, fatores associados a estilos de vida, dentre outros de natureza cultural, começam a influenciar 
mais as medidas de bem-estar (Inglehart, 2001, p. 79-80). Essa tendência decrescente não se verificaria apenas em indicadores concretos, mas também em medidas de bem-estar subjetivo, como o grau de felicidade e de satisfação com a vida (p. 80-82).

Essas análises levam o autor à afirmação de que, a partir de um ponto específico, o crescimento econômico gera apenas elevações mínimas nos indicadores de bem-estar, o que tornaria plausível e viável uma estratégia racional de valorização dos assuntos relacionados à qualidade de vida.

Como propõe a hipótese da socialização, a cultura não muda abruptamente, mas, com a elevação da segurança econômica, em um determinado momento, ela se alteraria e surgiriam novas formas de melhorar o bem-estar subjetivo através de mudanças nas prioridades e também nas normas e padrões de vida.

A complementaridade entre fatores econômicos e culturais torna-se evidente nesse raciocínio. De um lado, as condições socioeconômicas afetariam no longo prazo o sistema cultural; de outro, quando o sistema cultural se adapta às condições objetivas de existência passaria a influenciar a vida social, econômica e política. Novas estratégias de sobrevivência seriam criadas no contexto de segurança econômica e elas seriam as responsáveis pela continuidade na elevação nos níveis de satisfação material e subjetiva.

A partir desses argumentos, Inglehart defende que a impacto do desenvolvimento socioeconômico sobre as mudanças culturais ocorre em duas fases distintas. Na primeira, a da industrialização, teria surgido a burocratização e a secularização; na segunda, da pós-industrialização, ${ }^{1}$ a tendência se altera em direção à autonomia individual e aos valores de auto-expressão (Inglehart, 2001).

Os públicos das nações pós-industriais (mas não apenas delas) estariam gradualmente abandonando uma tendência materialista em 
favor de uma postura pós-materialista, ou seja, ao invés de priorizarem predominantemente metas relacionadas com a segurança física e econômica, estariam atribuindo valor crescente a outras metas, como necessidades sociais, estéticas ou intelectuais. Isso, todavia, não indicaria que tais públicos estão se tornando não-materialistas, muito menos anti-materialistas. O termo pós-materialismo, na realidade, é empregado no interior dessa perspectiva teórica para designar um conjunto de metas que são buscadas depois de alcançada a segurança material, e apenas porque ela foi alcançada (Inglehart, 2001).

As populações das nações dos países pós-industriais estariam experimentando desde o término da Segunda Guerra Mundial crescimento econômico expressivo, o que teria produzido altos níveis de segurança existencial, manifestos na elevação dos níveis de renda, ampliação da expectativa de vida e outros indicadores. Tal desenvolvimento teria diminuído sensivelmente os obstáculos que se impõem à autonomia, à criatividade e à possibilidade de escolha dos seres humanos (Inglehart, 2001).

Inglehart argumenta que os caminhos pelos quais esse processo estaria acontecendo são diversos. Primeiramente, a simples redução da pobreza diminuiria os constrangimentos à escolha humana e contribuiria para o desenvolvimento de um sentimento de segurança econômica e física. Também ampliaria os níveis educacionais das populações e favoreceria o acesso à informação através dos meios de comunicação de massa (Inkeles, 1983). A emergência da sociedade do conhecimento, por sua vez, mobilizaria as habilidades cognitivas dos indivíduos (Bell, 1973; Inglehart, 1990). Assim, o desenvolvimento econômico diminuiria os constrangimentos cognitivos e alimentaria a independência intelectual dos habitantes das sociedades pós-industriais.

Além disso, essa fase da modernização produziria uma ampliação da especialização ocupacional e uma maior complexidade 
social, diversificando as interações humanas e potencializando um processo já descrito por sociólogos clássicos, como Durkheim (1995) e Tonnies (1977), de passagem da solidariedade mecânica para a orgânica e da comunidade para a sociedade. Ao invés de normas e padrões fixos de comportamento, essa nova configuração social abriria espaço para as preferências individuais.

Sintetizando esse argumento, Inglehart e Wezel (2005, p. 24) escrevem que "[...] by reducing economic insecurity, by cognitive mobilization, and by diversifying human exchanges, socioeconomic development diminishes objective constraints on human choice." Ou seja, a teoria do desenvolvimento humano, aponta para uma situação em que, paulatinamente, os indivíduos ganham mais espaço como atores que aspiram à autonomia.

\section{Críticas às medidas de pós-materialismo}

As principais ferramentas empíricas empregadas pelos pesquisados da guinada pós-materialista são os índices propostos por Inglehart para medir a adesão dos indivíduos a objetivos e metas pós-materialistas. Inicialmente, o índice desenvolvido por esse pesquisador era calculado após a aplicação de uma bateria composta por 4 itens que representariam os seguintes objetivos ou metas prioritárias:

1) manter a ordem;

2) aumentar a participação dos cidadãos nas decisões importantes;

3) combater o aumento de preços;

4) proteger a liberdade de expressão. 
Os entrevistados eram convidados a escolher suas primeiras e segundas opções e, a partir de suas respostas, classificados como materialistas, mistos ou pós-materialistas (Inglehart, 1977).

Apesar de continuar sendo aplicada em alguns casos específicos, nos estudos posteriores essa medida foi substituída por um índice ampliado de 12 itens. À bateria inicial foram acrescentadas mais duas, cada uma delas com 4 itens. Os itens adicionais são os que seguem:

5) manter altas taxas de crescimento econômico;

6) assegurar que o país tenha importantes forças de defesa;

7) dar maior importância à opinião das pessoas sobre os assuntos em seu trabalho e comunidade;

8) fazer das cidades e paisagens mais bonitas;

9) manter a economia estável;

10) progredir em direção a uma sociedade menos impessoal e mais humana;

11) lutar contra a delinqüência;

12) progredir em direção a uma sociedade onde as idéias são mais importantes do que o dinheiro.

Diversos pesquisadores têm utilizado essas medidas e obtido resultados que tendem a confirmar as teses e hipóteses decorrentes da teoria do desenvolvimento humano em diferentes contextos sociais, políticos e econômicos (Abramson \& Inglehart, 1995; Dalton, 1996; Flanagan, 1982; Gibson \& Duch, 1994; Opp, 1990).

Entretanto, podemos também contabilizar um número significativo de pesquisas que pretendem criticar os pressupostos teóricometodológicos dessa abordagem e também produzir refutações empíricas das suas hipóteses (Boeltken \& Jagodzinski, 1985; Clarke \& Dutt, 1991; Clarke, Dutt \& Rapkin, 1997). 
Dentre esses trabalhos, gostaríamos de destacar especialmente aqueles que questionam a validade dos índices empregados por Inglehart como medidas estruturadas de valores. Como tais medidas são componentes indispensáveis à realização das diferentes análises empreendidas pelos adeptos da tese da guinada pós-materialista, o seu questionamento se constitui um duro golpe contra a teoria como um todo.

D. Davis e C. Davenport (1999, p. 650) são representantes importantes dessa perspectiva crítica, pois sugerem que "[...] respondents may select the individual items sincerely and meaningfully, and have preferences with respect to the priorities among the alternative items, without necessarily being 'materialist', 'postmaterialist', or 'mixed' in their broader political values".

Utilizando uma ampla coleção de dados de surveys realizados nos EUA, ${ }^{2}$ propõem verificar no nível micro a consistência do índice, empregando técnicas diferentes daquelas já utilizadas por Inglehart e seus colaboradores.

Segundo seus argumentos, a técnica de análise fatorial usualmente empregada para confirmar a validade das referidas medidas não seria adequada em razão da natureza dos dados produzidos pelas questões, uma vez que não seria capaz de especificar a matriz de covariância entre dados ordenados (Kim \& Mueller, 1990 apud Davis \& Davenport, 1999).

Em substituição, os autores propõem testes fundamentados em princípios básicos de probabilidade que, no seu conjunto, objetivam verificar se a classificação que resulta das questões sobre o materialismo/pós-materialismo são consistentes com um padrão de respostas aleatórias.

O raciocínio que sustenta os procedimentos propostos por esses autores é relativamente simples e pode ser assim sintetizado: na 
primeira questão - que envolve os 4 itens - a chance de selecionar uma opção pós-materialista é de 50\%, uma vez que existem 2 itens para cada pólo de valores. Na segunda questão, a chance de realizar essa mesma escolha é de 33\%, já que o item escolhido na primeira opção não pode ser repetido. As doze possíveis combinações em um processo aleatório de escolha revelam que 2 delas $(16,6 \%)$ resultam na categoria materialista, oito $(66,6 \%)$ na de mistos e $2(16,6 \%)$ na de pós-materialistas (Davies \& Devenport, 1999, p. 651).

A partir desses fundamentos, os autores verificam se a tendência global de respostas para a primeira e segunda questões sugere um padrão aleatório (16,6\% materialistas, $66,6 \%$ mistos e $16,6 \%$ pós-materialistas) e, em seguida, analisam se a probabilidade condicional de escolha na segunda questão de um item da mesma categoria da escolhida na primeira é maior do que a chance probabilística de 0,33.

Primeiramente, analisando as distribuições percentuais entre as três categorias geradas pelo índice em cada um dos nove surveys utilizados na pesquisa, constatam que entre o público norteamericano o percentual de materialistas foi se reduzindo. Entretanto, também afirmam que não existem evidências de que essa população esteja adotando valores pós-materialistas, uma vez que, em apenas um dos levantamentos, o percentual de indivíduos classificados nessa última categoria do índice ultrapassou o que poderia ser esperado aleatoriamente $(16,6 \%)$.

Apresentando os resultados do segundo teste, demonstram que em apenas 3 das 9 amostras a probabilidade de escolher uma opção pós-materialista, após a primeira opção dessa mesma natureza, foi superior ao que se poderia esperar em uma escolha aleatória (ou seja, 0,33).

A situação encontrada é diferente quando é analisada a probabilidade de uma escolha materialista suceder uma primeira 
escolha também desta ordem. Nesse caso, em nenhuma das amostras se verificou probabilidade menor do que a aleatória.

Ao cruzarem em uma tabela as respostas à primeira e segunda questão que compõe o índice, demonstraram que a distribuição não é consistente, ou seja, as opções dos indivíduos não estão significativamente associadas.

Davis e Davenport (1999, p. 655) também testaram o índice de 12 itens com os mesmos procedimentos descritos acima e verificaram que, apesar da sua maior sofisticação, as respostas não parecem ser estruturadas, em especial no que diz respeito ao pólo pós-materialista da dimensão, que se aproxima também de um padrão aleatório.

Tais resultados conduzem os autores à conclusão de que não existiria uma dimensão latente consistente que influenciasse os indivíduos a escolherem coerentemente opções de uma mesma orientação. Em termos mais explícitos, não existiria uma dimensão materialista/pós-materialista e a distribuição das respostas seguiria muito mais um padrão aleatório. Obviamente, esse tipo de afirmação questiona diretamente a validade da medida amplamente utilizada por Inglehart e seus colaboradores e impõe sérios problemas às pesquisas que têm se orientado por seus postulados fundamentais.

O trabalho desses dois pesquisadores, apesar de representativo, é apenas uma amostra do volume considerável de pesquisas contestadoras que a teoria do desenvolvimento humano tem suscitado. Outras várias investigações também mereceriam destaque nessa revisão, tais como as realizadas por Brown e Carmines (1995) e Bean e Papadakis (1994).

Infelizmente, seria impossível expor os argumentos de cada uma dessas contribuições no espaço de que dispomos aqui. É preciso, todavia, ter em mente que tais refutações se inserem em um terreno bastante polêmico e em hipótese alguma podem ser tomadas 
como definitivas, uma vez que muitas delas têm sido respondidas com argumentos interessantes pelos defensores da tese da mudança de valores.

O próprio Inglehart, com ajuda de colaboradores, se preocupou em rebater algumas das principais objeções de que tratamos acima. Primeiramente, Inglehart e Abramson (1999) discordam de uma afirmação recorrente entre os críticos de que pouca atenção teria sido dada à validação da medida de pós-materialismo no nível micro ou individual. Tal medida teria sido alvo de inúmeros testes desde a sua formulação original no início da década de 1970 e, a partir daí, de inúmeras outras análises que procuraram verificar sua validade.

Realmente, já na primeira obra de Inglehart (1977) sobre o tema, podemos encontrar uma considerável preocupação com a validação da bateria de itens que passou a ser utilizada largamente em pesquisas posteriores.

Como escrevemos acima, Davis e Davenport não desconhecem esses testes, porém, rejeitam-nos pelo fato de se valerem da técnica de análise fatorial que, supostamente, não poderia ser empregado para esse tipo específico de dados (1999, p. 650). Causa estranheza, entretanto, o fato dos autores apontarem essa suposta fragilidade metodológica apenas em uma nota de rodapé, sem qualquer discussão substantiva.

Contrariamente, Inglehart e Abramson (1999) defendem que tal técnica multivariada pode e tem sido usada amplamente para a análise de dados ordenados ou ipsativos, como os gerados pelas questões que compõem o índice.

$\mathrm{Na}$ verdade, reconhecem que a utilização de rankings pode causar dificuldades para o emprego da análise fatorial em razão do pequeno número de itens que normalmente são incluídos nesse tipo de formulação. A questão sobre qual número de itens seria o mais 
adequado para superar tais dificuldades é controversa, mas os autores acreditam que o fato do índice de materialismo/pós-materialismo ser formado por 12 itens (divididos em 3 baterias de 4 independentes umas das outras) reduziria os problemas envolvidos na aplicação dessa técnica (Inglehart \& Abramson, 1999, p. 666).

Entretanto, o fato mais importante apontado pelos autores é que esse problema metodológico atuaria contra a tese da mudança de valores. Ou seja, o emprego da análise reduziria a probabilidade de ser encontrada uma dimensão coerente que representasse a relação entre materialismo e pós-materialismo. Ainda assim, Inglehart e seus colegas têm recorrentemente encontrado evidências que confirmam a existência dessa dimensão.

Os autores explicam que o método de ordenamento tende a fazer com que cada item seja negativamente correlacionado com os demais itens do grupo, fazendo com que os dois primeiros ocupem pólos opostos na primeira dimensão e que o terceiro seja negativamente correlacionado com ambos. A despeito desse problema, Inglehart e seus colegas repetidamente têm encontrado em diferentes surveys um primeiro componente principal que explica parte considerável da variação na escolha dos itens. A explicação para essa recorrência estaria no simples fato de que "[...] some people choose materialist goals consistently, while others choose postmaterialist goals" (Inglehart e Abramson (1999, p. 666).

Como vimos, Davis e Davenport (1999), ao rejeitarem a análise fatorial, propõem como teste um experimento baseado em princípios probabilísticos e concluem que o índice não é válido pois as escolhas entre os itens se aproximam de uma distribuição aleatória. Inglehart e Abramson (1999) afirmam, entretanto, que um exame mais detalhado desse argumento revela sua fragilidade.

Primeiramente, apontam que o teste produzido pelos seus críticos só seria válido caso todos os itens presentes nas questões 
fossem igualmente desejáveis ou populares entre os entrevistados, o que não corresponde à realidade. Somente nessa situação irreal a ocorrência de percentuais inferiores a 33\% na segunda resposta poderia invalidar a medida. Na realidade concreta, os itens possuem níveis de popularidade distintos.

A título de exemplo, apontam que entre os norte-americanos entrevistados pelo World Value Survey na sondagem de 19901991, 54\% escolheram como prioridade o crescimento econômico, enquanto apenas $5 \%$ selecionaram o item "cidades mais bonitas" (Inglehart \& Abramson, 1999, p. 667). O fato de tão poucos priorizarem essa última opção não pode nos levar a concluir que se trata de uma escolha aleatória.

Para demonstrar o quanto inválido é o raciocínio probabilístico de Davis e Davenport, Inglehart e Abramson propõem a seguinte situação hipotética: $1 \%$ daqueles respondentes que escolheram uma primeira opção materialista escolhe na segunda questão o item pós-materialista $A ; 20 \%$ dos que na primeira questão priorizaram um item pós-materialista selecionem também o item $A$, ou seja, igualmente pós-materialista; assim, os pós-materialistas na primeira opção têm 20 vezes mais chances de selecionar o item $A$ como segunda escolha, em comparação com aqueles que selecionaram na primeira questão um item materialista. Ainda assim, segundo os argumentos dos críticos, como a freqüência de escolha desse item foi menor que $33 \%$, o padrão aleatório seria equivocadamente presumido (Idem).

As escolhas, portanto, dependeriam fundamentalmente da popularidade dos itens, logo, não seria possível estabelecer um percentual mínimo de ocorrência a partir do qual a hipótese da distribuição aleatória possa ser descartada. $\mathrm{O}$ que deveria ser verificado é "[...] whether those who initially selected postmaterialist goal $A$ are more likely to select postmaterialist goal $B$ than are those who initially selected one of the materialist goals (Idem). 
As críticas aqui apresentadas, bem como as respostas a elas dirigidas, representam uma pequena amostra da polêmica que as pesquisas sobre valores pós-materialistas têm gerado.

Acreditamos que essa polêmica seja indício da necessidade de investigações sobre sociedades especificas com a finalidade de captar particularidades que escapam ao analista em estudos que se debruçam sobre conjuntos relativamente amplos de nações, tais como os realizados por Inglehart e seus colaboradores. Estudos particulares são necessários, sobretudo, em realidades sociais, políticas e econômicas que se distanciam daquelas condições existentes nas chamadas sociedades pós-industriais.

Tentando contribuir minimamente para esse debate, na próxima seção apresentamos resultados de um conjunto de testes que tem como objetivo verificar se as medidas de valores empregadas nas pesquisas sobre pós-materialismo possuem consistência e validade no contexto nacional.

\section{Medidas de valores pós-materialistas no Brasil}

As evidências acumuladas ao longo de quase 30 anos de pesquisa pelos defensores da tese da mudança de valores atestam que o índice de materialismo/pós-materialismo é uma medida que atende aos requisitos científicos necessários para continuar a ser utilizada.

Entretanto, como essas validações foram realizadas através da análise agregada de dados internacionais, acreditamos que testes tomando sociedades específicas podem contribuir para a discussão sobre as potencialidades das medidas. Nesse sentido, ao invés de simplesmente supor a sua validade para o contexto brasileiro, apresentamos agora resultados de alguns testes realizados com dados produzidos pelas duas pesquisas conduzidas pelo projeto World 
Values Surveys (WVS) no Brasil, ${ }^{3}$ concluídas em 1991 e $1997 .{ }^{4}$ O WVS é uma grande investigação sobre mudanças socioculturais e políticas, executada por uma rede global de cientistas sociais a partir de surveys aplicados a amostras nacionais representativas de mais de 80 nações espalhadas por todos os continentes do planeta. As coletas de dados têm se repetido desde o início da década de 1980 em sucessivas ondas (1980-1984, 1990-1993, 1995-1997, 19992002 e 2005) e, na sua última edição concluída, produziu dados representativos para mais de $80 \%$ da população mundial.

Como parte de sua terceira onda de investigações, em 1991 o questionário mundial foi aplicado no Brasil a uma amostra representativa de 1.782 pessoas. Na onda subseqüente, a amostra nacional foi composta por 1.149 entrevistados.

Em todos os testes que apresentamos a seguir, as análises tomaram as duas amostras em separado, tendo como objetivo fundamental a identificação de possíveis tendências ao longo do tempo, ainda que a distância entre as duas coletas seja relativamente curta para compor uma série temporal satisfatória.

O primeiro dos testes que propomos é diretamente inspirado pelo debate travado entre Davis e Davenport (1999) e Inglehart e Abramson (1999) acerca da aleatoriedade das respostas ao índice de 4 itens e pretende identificar se existe consistência entre as escolhas dos indivíduos na primeira e na segunda opção.

Para tanto, realizamos o cruzamento entre as prioridades selecionadas pelos entrevistados nas duas escolhas. Como utilizamos diretamente a bateria de itens e não o índice gerado pela mesma, as variáveis envolvidas são medidas no nível nominal, sem ordenação. Sendo assim, utilizamos como medida de associação o coeficiente de contingência (C) (Barbetta, 2003).

Os resultados que encontramos indicam uma consistência significativa entre as respostas. Os valores para C são os primeiros 
dados que nos conduzem a essa conclusão, pois foram encontrados 0,60 e 0,55 (Tabela 1), respectivamente para cada amostra. Essa medida de associação varia de 0 a 1 , valores que representam, respectivamente, a independência total e a associação total. Nesse caso, portanto, podemos interpretar que as duas variáveis em questão estão associadas moderadamente.

Mas a riqueza desse relacionamento merece ser tratada em maiores detalhes. Verificamos que, na primeira amostra, a maioria (69,5\%) dos indivíduos que escolheram como primeira opção o item "manter a ordem" selecionaram na segunda opção o item "combater a alta dos preços" (Tabela 1). Na segunda amostra, apesar desse percentual cair para 48 pontos, a probabilidade de escolha desse item materialista é maior do que a da escolha de um item pósmaterialista.

Os resultados são semelhantes quando a ordem dos itens é invertida, ou seja, entre os entrevistados que selecionaram como primeira opção "combater a alta de preços", a maioria $(47,8 \%$ na primeira amostra e 53,1\% na segunda) escolheu na seqüência o item "manter a ordem".

Esses dados indicam uma considerável consistência nas escolhas materialistas dos entrevistados e indicam a existência de uma dimensão subjacente de valores estruturando as respostas.

Consistência tão forte como essa não é verificada quando analisamos as relações entre os itens pós-materialistas. Na primeira amostra, entre os indivíduos que selecionaram como primeira opção o item "aumentar a participação dos cidadãos", apenas $22 \%$ selecionaram como segunda alternativa a "proteção à liberdade de expressão". Nesse grupo verificamos que o item com maior probabilidade de ser selecionado como segunda opção é o combate à alta dos preços, com $64,1 \%$ de freqüência. Na segunda amostra, os percentuais são mais distribuídos, mas, ainda assim, 27,8\% dos 
membros desse grupo selecionaram o item "proteger a liberdade de imprensa" como segunda opção. Novamente o item referente à inflação foi o mais citado.

\section{Tabela 1 - Primeiras e segundas escolhas do índice de materialismo/pós-materialismo (4 itens)}

\begin{tabular}{|c|c|c|c|c|c|}
\hline \multirow{6}{*}{$\bar{\sigma}$} & \multirow[b]{2}{*}{$\begin{array}{c}\text { Prioridade } \\
1^{\mathrm{a}} \text { escolha } \\
(\%)\end{array}$} & \multicolumn{4}{|c|}{ Prioridade $2^{\mathrm{a}}$ escolha (\%) } \\
\hline & & $\begin{array}{c}\text { Manter a } \\
\text { ordem na } \\
\text { nação }\end{array}$ & $\begin{array}{l}\text { Aumentar a } \\
\text { participação } \\
\text { dos cidadãos }\end{array}$ & $\begin{array}{c}\text { Combater } \\
\text { a alta dos } \\
\text { preços }\end{array}$ & $\begin{array}{c}\text { Proteger a } \\
\text { liberdade } \\
\text { de } \\
\text { expressão }\end{array}$ \\
\hline & $\begin{array}{l}\text { Manter a } \\
\text { ordem na } \\
\text { nação }\end{array}$ & - & 21,9 & 69,5 & 8,6 \\
\hline & $\begin{array}{l}\text { Aumentar a } \\
\text { participação } \\
\text { dos cidadãos }\end{array}$ & 13,9 & - & 64,1 & 22,0 \\
\hline & $\begin{array}{l}\text { Combater } \\
\text { a alta dos } \\
\text { preços }\end{array}$ & 47,8 & 34,9 & - & 17,3 \\
\hline & $\begin{array}{l}\text { Proteger a } \\
\text { liberdade de } \\
\text { expressão }\end{array}$ & 15,6 & 53,2 & 31,2 & - \\
\hline \multirow{4}{*}{$\hat{\sigma}$} & $\begin{array}{l}\text { Manter a } \\
\text { ordem na } \\
\text { nação }\end{array}$ & - & 34,8 & 48,0 & 17,2 \\
\hline & $\begin{array}{l}\text { Aumentar a } \\
\text { participação } \\
\text { dos cidadãos }\end{array}$ & 30 & - & 42,2 & 27,8 \\
\hline & $\begin{array}{l}\text { Combater } \\
\text { a alta dos } \\
\text { preços }\end{array}$ & 53,1 & 29,2 & - & 17,7 \\
\hline & $\begin{array}{l}\text { Proteger a } \\
\text { liberdade de } \\
\text { expressão }\end{array}$ & 33,3 & 38,2 & 28,1 & - \\
\hline $\begin{array}{l}\text { Para } \\
\text { Para }\end{array}$ & $\begin{array}{ll}991: & N=1742 \\
997: & N=1141\end{array}$ & $\begin{array}{l}\mathrm{C}=0,61 \\
\mathrm{C}=0,55\end{array}$ & $\begin{array}{l}p=0,000 \\
p=0,000\end{array}$ & & \\
\hline
\end{tabular}


Não acreditamos, entretanto, que essa inconsistência se deva a possíveis fragilidades do índice, de modo que propomos uma interpretação alternativa.

A relativa incongruência nas prioridades desse grupo de indivíduos - que poderíamos aqui classificar como "participacionistas", uma vez que selecionaram como objetivo mais importante a ampliação da participação dos cidadãos nos assuntos importantes -, pode ser um indício do quanto os valores democráticos ainda não estão consolidados na cultura política nacional. Considerando os resultados encontrados pelas pesquisas nacionais sobre esse assunto, acreditamos ser plausível supor que a liberdade de expressão e a ampliação da participação política possam estar desconectadas na visão de nossa população.

Recentemente, Moisés (2006) chamou nossa atenção para o inusitado fato de uma parcela significativa da população nacional apoiar uma espécie de democracia sem congresso. Algo semelhante pode ser sugerido pela inconsistência verificada no teste que estamos apresentando. Ou seja, é possível que os "participacionistas" não vejam a liberdade de expressão como condição para a participação. É claro que por trás dessa dissociação pode estar tanto a percepção de que tal liberdade já esteja plenamente garantida no contexto social, quanto a de que ela não é realmente importante.

Um elemento concreto pode também ter conduzido a essa relativa desconsideração da liberdade de expressão: a elevada taxa de inflação verificada no momento da coleta dos dados.

Inglehart $(1990,2001)$ em suas análises tratou de demonstrar o impacto que a oscilação nas taxas de inflação pode causar nas prioridades valorativas individuais. Mas, também destacou que esses efeitos atuam apenas no curto prazo, não alterando significativamente a trajetória de mudanças culturais explicadas pelas hipóteses da escassez e da socialização. 
Segundo a Fundação Instituto de Pesquisas Econômicas (FIPE), o acumulado do Índice de Preços ao Consumidor Geral (IPC Geral) em 1991 foi de $458,61 \%$, o que poderia ter tornado o item referente à inflação algo de grande relevância para os entrevistados. De fato, esse item foi o mais popular entre os indivíduos que compõem as duas amostras, sendo a primeira opção de 43,2\% dos entrevistados em 1991 e de 32\% em 1997.

A comparação desses efeitos entre os dois períodos de coleta de dados também nos fornece informações importantes. Como mencionamos no parágrafo anterior, a popularidade do item "combater o aumento de preços" perde mais de 10 pontos percentuais entre 1991 e 1997. Essa redução da preocupação com a inflação, provavelmente, deve-se ao fato de que, em 1997, a inflação tenha sido de apenas 4,83 pontos.

Essa também poderia ser a explicação para a redução da probabilidade do referido item materialista ser escolhido como segunda alternativa pelos "participacionistas" da amostra de 1997.

A inconsistência na dimensão pós-materialista desaparece quando voltamos nossa atenção para o grupo dos indivíduos que selecionaram como primeira opção o item "proteger a liberdade de imprensa". Entre esses entrevistados, 53,2\% selecionaram, na segunda opção, o item pós-materialista "aumentar a participação dos cidadãos" na primeira amostra, e 38,2\%, na pesquisa seguinte. Mesmo nesse segundo momento, quando o percentual sofreu uma redução de aproximadamente 15 pontos percentuais, a probabilidade de seleção do item pós-materialista ainda é maior (Tabela 2).

Propomos, como segundo teste, a verificação das associações existentes entre as três baterias que compõem o índice de materialismo/pós-materialismo de 12 itens. Partindo dos resultados da análise anterior, as medidas derivadas das duas baterias adicionais serão consideradas como adequadas se os seus relacionamentos com a bateria original forem estatisticamente significativos e positivos. 
Para operacionalizar essa análise, alguns procedimentos de recodificação e computação das variáveis foram necessários e, para fins de reprodutibilidade, vamos agora descrevê-los.

Inicialmente recodificamos as variáveis de cada uma das baterias agrupando os itens materialistas no valor " 0 " e os itens pósmaterialistas no valor "1". Após essa recodificação, construímos um índice somatório para cada bateria, de modo que passamos a possuir três medidas de materialismo/pós-materialismo distintas. Nos três índices, os valores possíveis são os seguintes: "0" quando na primeira e segunda opção da bateria forem escolhidos itens materialistas; "1" quando ocorrer a combinação de um item materialista com outro pós-materialista; "2" quando dois itens pós-materialistas forem selecionados nas duas escolhas de uma bateria. As três medidas, portanto, vão de 0 a 2 .

Os resultados do teste aparecem na Tabela 2 e indicam que as associações entre as três medidas são estatisticamente significativas e positivas, ainda que os coeficientes sejam baixos, sobretudo no caso da associação entre a primeira e a terceira. Ainda que não revelem uma correlação elevada, os dados corroboram a tese de que existe uma dimensão de valores materialistas/pós-materialistas estruturando as respostas obtidas com o emprego das 3 baterias de itens.

Finalmente, como último teste envolvendo os índices, apresentamos a seguir resultados de análise fatorial envolvendo as três medidas derivadas das baterias de itens que já destacamos. Esse procedimento é uma técnica multivariada que visa, principalmente, reduzir uma quantidade significativa de variáveis a um grupo restrito de dimensões ou fatores. Trata-se, portanto, de uma ferramenta para a verificação de interdependências que permite a criação de variáveis latentes que agrupam variáveis observadas (Hair, Anderson \& Tatham, 1998). 
Tabela 2 - Correlações entre as medidas de materialismo/ pós-materialismo

\begin{tabular}{|c|c|c|c|}
\hline \multirow{4}{*}{1991} & & MEDIDA 1 & MEDIDA 2 \\
\hline & Medida 1 & & \\
\hline & Medida 2 & $0,14^{* * *}$ & \\
\hline & Medida 3 & $0,09^{* * *}$ & $0,22^{* * *}$ \\
\hline \multirow{3}{*}{1997} & Medida 1 & & \\
\hline & Medida 2 & 0,15 & \\
\hline & Medida 3 & $0,06^{*}$ & 0,17 \\
\hline
\end{tabular}

Nota: ${ }^{* *} p=0,01 .{ }^{*} p=0,05$.

Fonte: European and World Values Surveys four-wave Integrated data file, 1981-2004, v.20060423, 2006.

No presente caso, a técnica é empregada para verificar se existe uma estrutura latente que possa explicar satisfatoriamente a variação das três medidas de valores. A consistência do índice de materialismo/pós-materialismo de 12 itens só pode ser afirmada caso exista uma dimensão única envolvendo as respostas obtidas com cada uma das baterias de itens.

A Tabela 3 traz os resultados da análise e aponta para a existência dessa dimensão. Como podemos verificar, as cargas fatoriais são, na sua maioria, elevadas, sendo apenas uma delas (medida 1 da primeira amostra) menor que 0,6.

Essas cargas indicam a comunalidade existente entre os itens (ou variáveis observadas) e o fatorgerado (variável latente ou estrutura dimensional). Dessa forma, a interpretação dos valores, considerando a primeira amostra, é a seguinte: a segunda medida é explicada em $74 \%$ pelo fator, a terceira em $68 \%$ e assim sucessivamente. Esse componente principal, correspondente à dimensão materialista/pósmaterialista, pode explicar $43,47 \%$ e $41,58 \%$ da variação total das medidas, em cada amostra respectivamente. 


\section{Tabela 3 - Cargas fatoriais e variação explicada por um único fator para as três medidas}

\begin{tabular}{|c|c|c|}
\hline \multirow{5}{*}{ बू } & & MPONENTE \\
\hline & Medida 1 & 0,53 \\
\hline & Medida 2 & 0,74 \\
\hline & Medida 3 & 0,69 \\
\hline & \% Variação Explicada & 43,47 \\
\hline \multirow{4}{*}{$\hat{a}$} & Medida 1 & 0,59 \\
\hline & Medida 2 & 0,73 \\
\hline & Medida 3 & 0,60 \\
\hline & \% Variação Explicada & 41,58 \\
\hline
\end{tabular}

Nota: Método de extração - Componentes Principais. Sem rotação.

Tais valores confirmam os resultados dos testes anteriores ao indicar a possibilidade de redução das diferentes medidas a um índice consistente único que pode medir as prioridades valorativas dos indivíduos. As respostas fornecidas pelos entrevistados brasileiros, em ambas as amostras, afastam-se consideravelmente de um padrão aleatório, sendo significativamente estruturadas, conforme prevê a teoria do desenvolvimento humano.

O conjunto dessas análises, portanto, acrescenta argumentos favoráveis à validação das medidas empregadas nos estudos sobre mudanças de valores para investigações no contexto nacional.

\section{Considerações finais}

A teoria do desenvolvimento humano tem orientado um conjunto de pesquisadores na realização de investigações ao redor do mundo acerca de uma mudança nas prioridades valorativas individuais e nas metas societais. Os resultados encontrados nessas análises, de uma maneira geral, têm indicado que uma síndrome de 
valores pós-materialistas estaria ocorrendo principalmente entre as nações industrialmente avançadas que, gradualmente, estariam abandonando estratégias desenvolvimentistas e maximizadoras do lucro. Preocupações com a qualidade de vida, com a preservação ambiental e com a auto-expressão estariam despontando como novas prioridades nessas sociedades.

Apesar de relativamente bem-sucedida, essa tese fundamental tem também conquistado críticos contundentes. Neste artigo destacamos uma dessas perspectivas críticas, relacionada a uma dimensão metodológica e empírica dos estudos em questão. Mais especificamente, tratamos de uma suposta fragilidade dos índices de materialismo/pós-materialismo desenvolvidos por R. Inglehart e empregados pelos estudiosos da citada mudança cultural como ferramenta de pesquisa fundamental.

Mediante a realização de testes estatísticos envolvendo amostras nacionais, procuramos contribuir para essa discussão verificando em que medida os indicadores em questão possuem consistência e validade no contexto brasileiro específico. Nossas conclusões corroboraram a teoria do desenvolvimento humano ao indicarem claramente que o conjunto das respostas fornecidas pelos entrevistados não seguem um padrão aleatório, tal como afirmam os críticos. Ao invés disso, identificamos que as prioridades manifestas pelos indivíduos nas duas amostras possuem significativa coerência interna e, ao que tudo indica, podem ser satisfatoriamente representadas por uma única dimensão que opõe tendências materialistas a pós-materialistas.

\section{Notas}

1 Em Modernization and postmodernization, Inglehart não se refere às duas fases da modernização, utilizando o termo pós-modernização para designar a nova configuração social das sociedades desenvolvidas. 
2 As coleções de dados são as seguintes: American National Election Study de 1972, 1976, 1980, 1984, 1988 e 1992; General Social Survey de 1993 e 1994; World Values Survey de 1991 (componente norteamericano).

3 Esses dados estão presentes na base integrada v20060423, que reúne as bases de todas as pesquisas realizadas pelo WVS e também pelo European Values Surveys desde 1980. Essa base integrada está disponível no endereço http://www.worldvaluessurvey.org/ sob o código xwvsevs_ 1981_2000_v20060423. Aproveitamos a oportunidade para agradecer a Ronald Inglehart, presidente do WVS, por disponibilizar os dados.

4 Infelizmente, a última onda de pesquisas conduzidas por essa organização não incluiu o Brasil.

The consistence of postmaterialistic values: testing the validity of $R$. Inglehart's indexes applied in Brazilan context

Abstract: The theory of the human development, defended by R. Inglehart, postulates that a slow and gradual change in the individual priorities has been happening in world scale in the last decades. That alteration would be leading to the adoption of postmaterialistic values that emphasize the life quality and the self-expression as individual goals. The indexes built by that researcher to measure such priorities, however, had been object of several critics on their validity and consistence. In this article, is presented a group of tests involving those indexes for the specific Brazilian case, with the objective of contributing with that theoretical-methodological debate. Using data produced by the project World Values Survey and using different statistical techniques, the authors identified that the measures in subject present significant consistence in Brazilian context.

Keywords: human development, postmaterialism, values, measures of values, R. Inglehart. 


\section{Referências}

ABRAMSON, Paul; INGLEHART, Ronald. Value change in global perspective. Ann Arbor: University of Michigan Press, 1995.

BARBETTA, Pedro A. Estatística aplicada às ciências sociais. 5. ed. Florianópolis: Ed. da UFSC, 2003.

BEAN, Samuel H; PAPADAKIS, Elim. Polarized priorities or flexible alternatives? Dimensionality in the Materialism-Postmaterialism Scale. International Journal of Public Opinion Research v. 6, n. 3, p. 264-88, 1994.

BELL, Daniel. The coming of postindustrial society. New York, Basic Books, 1973.

BOELTKEN, Ferdinand; JAGODZINSKI, Wolfgang. Postmaterialism in the European Community, 1970-1980: insecure value orientations in an environment of insecurity. Comparative Political Studies, n. 17, p. $453-84,1985$.

CLARKE, Harold D; DUTT, Nitish. Measuring value change in western industrialized societies: the impact of unemployment. American Political Science Review, n. 85, p. 905-20, 1991.

CLARKE, Harold D. et al. The effect of economic priorities on the measurement of value change: new experimental evidence. American Political Science Review n. 93, p. 637-47, 1999.

CLARKE, Harold; DUTT, Nitish; RAPKIN, Jonathan. Conversation in context: the (mis) measurement of value change in advanced industrial societies. Political Behavior, n. 19, p. 19-40, 1997.

DALTON, Russell J. Citizen Politics. 2. ed. New Jersey: Chatham House, 1996.

DAVIS, Darren; DAVENPORT, Christian. Assessing the validity of the Postmaterialism Index. American Political Science Review, n. 93, p. 649-64, 1999.

DAWKINS, Richard. The selfish gene. Oxford: Oxford University Press, 1989.

DURKHEIM, Emile. Da divisão do trabalho social. São Paulo: Martins Fontes, 1995. 
FLANAGAN, Scott C. Changing values in advanced industrial society. Comparative Political Studies, n. 14, p. 403-44, 1982.

GIBSON, James L.; DUCH, Raymond M. Postmaterialism and the emerging soviet democracy. Political Research Quarterly, n. 47, p. 5-39, 1994.

HAIR, Joseph; ANDERSON, Ralph; TATHAM, Ronald. Multivariate data analysis. 2. ed. New York:Macmillan, 1987.

INGLEHART, Ronald. The silent revolution. Princeton: Princeton University Press, 1977.

. Culture shift in advanced industrial society. Princeton: Princeton University Press, 1990.

. Modernización y posmodernización: el cambio cultural, económico y político en 43 sociedades. Madrid: Centro de Investigaciones Sociológicas/Siglo Veintiuno, 2001.

INGLEHART, Ronald; ABRAMSON, Paul. Measuring postmaterialism. American Political Science Review, n. 93, p. 665-77, 1999.

INGLEHART, Ronald; WELZEL, Christian. Modernization, cultural change, and democracy: the human development sequence. New York: Cambridge University Press, 2005.

INKELES, Alex. Exploring individual modernity. New York: Columbia University Press, 1983.

MASLOW, Abraham. Motivation and Personality. New York: Harper \& Row, 1988.

MOISÉS, José A. A avaliação das instituições democráticas e a qualidade da democracia no Brasil. Comunicação apresentada no $3^{\circ}$ Congresso Latino-americano de Ciência Política. Campinas: UNICAMP, 2006.

OPP, Karl-Dieter. Postmaterialism, collective action, and political protest. American Journal of Political Science, n. 34, p. 212-35, 1990.

TÖNNIES, Ferdinand. Comunidade e sociedade In: BIRNBAUM, P.; CHAZEL, F. Teoria sociológica. São Paulo: Hucitec-Edusp, 1977. 